\title{
STUDIES ON A PROTEOLYTIC ENZYME IN HUMAN PLASMA. VII. A FATAL HEMORRHAGIC STATE ASSOCIATED WITH EXCESSIVE PLASMA PRO- TEOL.YTIC ACTIVITY IN A PATIENT UNDERGOING SURGERY FOR CARCINOMA OF THE HEAD OF THE PANCREAS ${ }^{1}$
}

\author{
BY OSCAR D. RATNOFF 2 \\ (From the Departments of Medicine, The Western Reserve University School of Medicine and \\ the Mount Sinai Hospital, Cleveland, Ohio)
}

(Submitted for publication January 21, 1952; accepted March 24, 1952)

Human plasma contains a proteolytic enzyme system which can digest fibrinogen and fibrin. This enzyme system appears to be in an inactive form in the circulating plasma, but its presence can be demonstrated in a number of ways in shed blood. This in vitro proteolytic activity seems to be influenced by the physiologic state of the subject from whom the blood is obtained. Abnormally rapid fibrinolysis has been observed in blood drawn from patients with a wide variety of diseases (1-3). Rapid fibrinolysis has also been seen in the blood of patients undergoing electric shock therapy (4), and in patients with shock as the result of burns or hemorrhage (5).

The possibility that a hemorrhagic state may result from the destruction of prothrombin or fibrinogen by the plasma proteolytic enzyme has been postulated repeatedly (5-7). A number of patients have been described in whom a hemorrhagic state was associated with excessive plasma fibrinolytic activity $(5,8,9)$. These patients were thought to have little or no fibrinogen in their circulating plasma.

Additional evidence that hemorrhage may be associated with activity of the proteolytic enzyme of plasma has been provided by the study of a patient with carcinoma of the head of the pancreas. During the second stage of a pancreatectomy, uncontrollable hemorrhage occurred from multiple sites. The patient's blood, obtained two and a half hours before death, contained appreciable amounts of prothrombin and fibrinogen. However, the patient's whole blood failed to clot in glass tubes at $37^{\circ} \mathrm{C}$. A circulating anticoagulant was not demonstrable, but her plasma appeared

\footnotetext{
1 This study was supported by a grant from The Cleveland Area Heart Society.

2 Present address: University Hospitals, Cleveland, Ohio.
}

to have extreme fibrinogenolytic and fibrinolytic properties. It was concluded that the patient's blood failed to clot because the fibrinogen it contained was destroyed before any detectable quantity of fibrin formed.

\section{CASE REPORT}

N. J. (Mt. S. No. 7640), a 42 year old colored woman, was hospitalized on July 27, 1951 because of right upper abdominal pain and soreness for the preceding week. She had always bruised easily, had twice bled profusely after dental extractions, and had had one severe epistaxis. The patient had rectal bleeding, first noted in 1948, associated with external and internal hemorrhoids. A barium enema and sigmoidoscopy revealed no abnormality.

In April, 1950, her bleeding time was one minute, clotting time was three minutes (capillary tube method), prothrombin time was 14.8 seconds, the platelet count was 146,300 and clot retraction was observed in 45 minutes. These values were normal for the techniques then in use.

The remainder of the patient's past history was not unusual. A thyroid adenoma was observed in August, 1950; the basal metabolic rate was plus two. There was no history of menorrhagia or metrorrhagia. Her 10 pregnancies were without hemorrhagic complications. There was no family history of hemorrhagic disease.

For the five weeks before her hospitalization, the patient had intermittent right upper quadrant pain and tenderness, excessive eructation, and anorexia. She was treated during this period with a low fat diet and lost about 13 pounds. During the week before admission, she had nausea, "heart burn" and transient diarrhea. Four days before admission her urine was dark and her stools white. Her last menses began 10 days before hospitalization and lasted seven days, an excessively long time for the patient.

At the time of admission, the patient did not appear to be ill. The sclerae were icteric and the edge of the liver was palpated about $5 \mathrm{~cm}$. below the costal margin; two observers thought the tip of the spleen was palpable. The urine was brown and contained bile pigments; a two hour specimen had from 0.2 to 0.7 Ehrlich units of urobilinogen. The red blood cell count was 4.27 million, the hemoglobin was 12.5 grams (Sahli), and the hematocrit, 
41 per cent. The white blood cell count was 10,350; the differential count was unremarkable and platelets were plentiful in the smear. The stools were clay colored and tests for stercobilin and stercobilinogen were negative. The serologic test for syphilis was negative. The concentration of bilirubin in the serum was $9.0 \mathrm{mg}$., albumin, 4.9 grams, globulin, 3.1 grams, non-protein nitrogen, 25 mg., total cholesterol, $187 \mathrm{mg}$., esterified cholesterol, 78 mg., and sugar, $114 \mathrm{mg}$. per $100 \mathrm{ml}$. The cephalin cholesterol flocculation test was four plus and the thymol turbidity was 1.7 Maclagan units. The serum alkaline phosphatase activity was 16.9 Bodansky units and gradually increased during the next two weeks to 30.6 units. The prothrombin time was 17.9 seconds; the control time was 15.7 seconds. On August 17, the plasma fibrinogen concentration was $555 \mathrm{mg}$. per $100 \mathrm{ml}$., an abnormally high value. $\mathrm{X}$-rays of the chest, stomach and upper intestine showed no abnormalities. The gall bladder could not be visualized on two occasions by oral cholecystography.

On August 20, 1951, an exploratory laparotomy revealed chronic pancreatitis and an adenocarcinoma of the pancreas invading the first portion of the duodenum. The distal one-fourth of the stomach was removed, a gastroenterostomy and cholecystojejunostomy were performed, and a T-tube was placed in the common duct. - During the operation, almost continuous oozing of blood was noted from the exposed serosal surfaces. Nine days post-operatively, cholangiograms revealed a fusiform narrowing of the common duct distal to the T-tube.

On September 13, the clotting time was 21 minutes, a normal value, and the prothrombin time was $20.1 \mathrm{sec}-$ onds, compared with a normal of 16.8 seconds.

A second operation was performed September 14. After premedication with seconal, demerol, and scopolamine, anesthesia was induced with pentothal and maintained with cyclopropane. The scar of the previous incision was excised, and the incision was extended to a row of interrupted wire sutures inserted at the previous operation. These wires were removed without excessive bleeding. A transfusion of citrated bank blood was begun at this time, 15 minutes after the start of the operation. The abdominal cavity was then entered preparatory to a pancreatectomy. Forty-five minutes after the beginning of the operation, while the surgeon was freeing adherent loops of intestine to reach the pancreas, the patient's blood pressure suddenly fell from $130 / 80$ to $80 / 50 \mathrm{~mm}$. of mercury. The pulse rate was 95 per minute and the skin was warm and dry. Blood began to ooze from the omental and serosal surfaces, but a discrete bleeding point could not be found. The hemorrhage grew progressively more profuse, and was uncontrollable. The blood pressure gradually fell, and the patient expired five hours after the operation had begun. At the time of death, approximately 5 liters of unclotted blood had collected in the peritoneal cavity. The patient had hematomas at the sites of venous and arterial punctures, and blood flowed from a Levine tube inserted into the stomach. Among the unsuccessful measures used to con- trol the patient's hemorrhages were the transfusion of $4,000 \mathrm{ml}$. of citrated bank blood, and the intravenous injection of $10 \mathrm{ml}$. of a 10 per cent solution of calcium gluconate and $5 \mathrm{ml}$. of a one per cent solution of protamine sulfate.

The patient's blood was Group $\mathrm{O} \mathrm{Rh}_{1} \mathrm{Rh}_{2}$. The blood of each of the eight blood donors was also Group $\mathrm{O}, \mathrm{Rh}$ positive. No incompatibility was demonstrable between the patient's serum and any of the donors' cells, or vice versa. The cross-matchings were rechecked post mortem by both slide and tube-methods, using both saline and 30 per cent bovine albumin as diluents. The donors were retyped, and their bloods were again compatible with the patient's. The patient's urine, obtained post mortem, was negative for hemoglobin when tested with orthotolidene and benzidene. Her plasma, about 120 minutes after the initial fall of blood pressure, contained $18 \mathrm{mg}$. of hemoglobin per $100 \mathrm{ml}$.

The initial donor's blood contained agglutinins in a titer of 1:16 against trypsin-treated normal Group $\mathrm{O}, \mathrm{Rh}$ positive and $\mathrm{Rh}$ negative red blood cells, and the patient's trypsin-treated red cells. One week later, a fresh specimen of this donor's blood contained agglutinins against trypsin-treated red cells in a titer of $1: 4$. The direct and indirect Coombs tests of the patient's blood and each of the donors' bloods were negative.

At the operation, the diagnosis of adenocarcinoma of the pancreas was confirmed by biopsy. The tumor cells had invaded both lymphatic and venous channels. A specimen of liver was smooth, glistening and yellowishgreen. Histologically, there was early biliary cirrhosis. Permission for autospy was not obtained.

\section{METHODS}

Three hours after the induction of anesthesia, two hours after bleeding was first noted, blood was drawn from the right jugular vein through a No. 18 gauge needle, using silicone-treated equipment. At this time, the patient had already received approximately $3,000 \mathrm{ml}$. of citrated blood. A portion of the blood drawn was used to measure the whole blood clotting time. Another portion was transferred to silicone-lined lusteroid tubes and the cells were removed by high speed centrifugation at low temperatures $(10,11)$. This platelet-deficient native plasma contained one platelet per $\mathrm{mm}^{3}$. Still another portion of blood was decalcified by mixing one part of $0.1 \mathrm{M}$. sodium oxalate with nine parts of whole blood, centrifuged, and the supernatant plasma used in all tests requiring oxalated plasma except the determination of fibrinogen. A fourth portion was mixed with dry oxalate salts in a proportion of $5 \mathrm{ml}$. of whole blood to $6 \mathrm{mg}$. of ammonium oxalate and $4 \mathrm{mg}$. of potassium oxalate. This oxalated plasma was used to measure plasma fibrinogen.

Determination of clotting time. One $\mathrm{ml}$. of blood was transferred immediately to each of three dry pyrex tubes (internal diameter, $11 \mathrm{~mm}$.) which were stoppered and incubated at $37^{\circ} \mathrm{C}$. Starting five minutes after the blood was drawn, the first tube was observed for clotting by tilting it about once a minute. Sixty, 120, and $180 \mathrm{~min}-$ 
utes after the blood was drawn, the second and third tubes were also tilted. Thereafter, the third tube was examined frequently for 24 hours. The clotting time of platelet-deficient plasma was determined in the same way in duplicate. After the contents of the first tube had clotted, the second was tilted about once a minute for an additional 90 minutes.

Determination of prothrombin time. The prothrombin time was determined in duplicate at $37^{\circ} \mathrm{C}$. by mixing 0.1 $\mathrm{ml}$. of oxalated plasma and $0.2 \mathrm{ml}$. of equal parts of thromboplastin (Chilcott) and $0.025 \mathrm{M}$. calcium chloride, in pyrex tubes (internal diameter, $8 \mathrm{~mm}$.).

Determination of fibrinogen content of plasma. The fibrinogen content of plasma was determined by a previously described method (12).

Preparation of fibrinogen solution. Desiccated bovine fibrinogen 2 was dissolved in barbital buffer $(0.125 \mathrm{M}$. sodium chloride and $0.025 \mathrm{M}$. barbital at $\mathrm{pH} 7.5$ ), and the undissolved small residue was removed by filtration through No. 1 Whatman filter paper. In each experiment, then, the concentration of fibrinogen was something less than the recorded concentration.

Determination of fibrinolytic activity of plasma. Oxalated plasma was diluted serially with barbital buffer. Three-tenths $\mathrm{ml}$. of diluted plasma was mixed with $0.3 \mathrm{ml}$. of a solution of bovine fibrinogen (330 mg. per $100 \mathrm{ml}$.) in pyrex tubes (internal diameter, $8 \mathrm{~mm}$.). This mixture was then clotted with $0.1 \mathrm{ml}$. of a solution of bovine thrombin $^{8}$ (10 N.I.H. units per $\mathrm{ml}$.). The tubes were stoppered, incubated at $37^{\circ} \mathrm{C}$., and observed for lysis.

Determination of inhibitory activity of plasma against plasma proteolytic enzyme. The inhibitory activity of plasma against the plasma proteolytic enzyme was tested against purified bovine plasma proteolytic enzyme.4 The enzyme was dissolved in buffer and standardized in the following manner: The enzyme solution was serially diluted with buffer, $0.3 \mathrm{ml}$. of each dilution was pipetted into pyrex tubes (internal diameter, $8 \mathrm{~mm}$.) and mixed with $0.3 \mathrm{ml}$. of buffer and $0.1 \mathrm{ml}$. of a solution of thrombin (10 N.I.H. units per ml.). The tubes were placed in an ice bath, and $0.3 \mathrm{ml}$. of fibrinogen solution $(330 \mathrm{mg}$. per $100 \mathrm{ml}$.) was added. The mixtures were then transferred to a water bath at $37^{\circ} \mathrm{C}$., and the clots which formed were observed for lysis. The concentration of bovine plasma proteolytic enzyme which completely lysed this standard fibrin clot in 10 minutes was 2.5 units per $\mathrm{ml}$.

The patient's oxalated plasma was serially diluted with buffer, and $0.3 \mathrm{ml}$. of each dilution was mixed with 0.3 $\mathrm{ml}$. of a solution of bovine enzyme ( 2.5 units per $\mathrm{ml}$.) and incubated at $37^{\circ} \mathrm{C}$. for 10 minutes. The mixtures were iced and $0.3 \mathrm{ml}$. of fibrinogen and $0.1 \mathrm{ml}$. of thrombin were

\footnotetext{
2 Bovine fibrinogen was obtained through the courtesy of Dr. Walter Seegers.

8 Bovine thrombin was obtained through the courtesy of Parke, Davis \& Company, Detroit.

- Bovine fibrinolysin (plasma proteolytic enzyme) obtained through the courtesy of Parke, Davis \& Company, Detroit.
}

added. The tubes were then incubated at $37^{\circ} \mathrm{C}$., and the clots which formed were observed for lysis.

Determination of anticoagulant activity of plasma. The anticoagulant activity of plasma was tested by measuring its clot-retarding effect on normal blood (13).

Determination of thrombin-inhibitory activity of plasma. The clotting time of equal parts of the patient's plasma, a solution of bovine fibrinogen (250 mg. per $100 \mathrm{ml}$.), and a solution of bovine thrombin, serially diluted, was measured at $37^{\circ} \mathrm{C}$. in pyrex tubes (internal diameter, $8 \mathrm{~mm}$.). The clotting time of this mixture was also determined, replacing fibrinogen with prothrombin-deficient plasma, prepared by incubation with one-fifth its volume of powdered barium sulfate at $37^{\circ} \mathrm{C}$. for 10 minutes.

\section{RESULTS}

Venous blood, drawn two hours after the patient began to bleed, failed to clot in glass tubes within 24 hours. Platelet-deficient native plasma was prepared from blood drawn at the same time and its clotting time was determined in duplicate. Strands of fibrin appeared within $28 \mathrm{~min}$ utes in the first tube, and clotting appeared to be complete 10 minutes later. This clot did not seem as solid as that of normal plasma, but it was not displaced when the tube was inverted. At this time, observation of the second tube was begun. No clot was seen in this second tube during the next 90 minutes. Eleven minutes after the plasma in the first tube had clotted, the clot lysed completely. These observations suggested that the patient's plasma contained those elements necessary for clotting to take place within a normal time, but it possessed excessive fibrinolytic activity.

The fibrinolytic activity of plasma is due to the presence of a proteolytic enzyme which can also digest prothrombin (14) and fibrinogen. The possibility was studied that whole blood failed to clot because of the activity of this enzyme. Three hours and 15 minutes after the blood was drawn, 0.1 and $0.5 \mathrm{ml}$. of a solution of bovine thrombin (1,000 N.I.H. units per ml.) were added, respectively, to the unclotted blood in the first and second tubes used to determine the clotting time. No clots were seen in either tube during the next four days. Similarly, 108 minutes after the start of the test for the clotting time of platelet-deficient plasma, the addition of 100 units of thrombin did not result in clotting in the second, unclotted tube.

There are at least two interpretations of these experiments. Either the blood failed to clot due 
TABLE I

The effect of thrombin on the clotting time of a mixture of oxalated plasma and fibrinogen

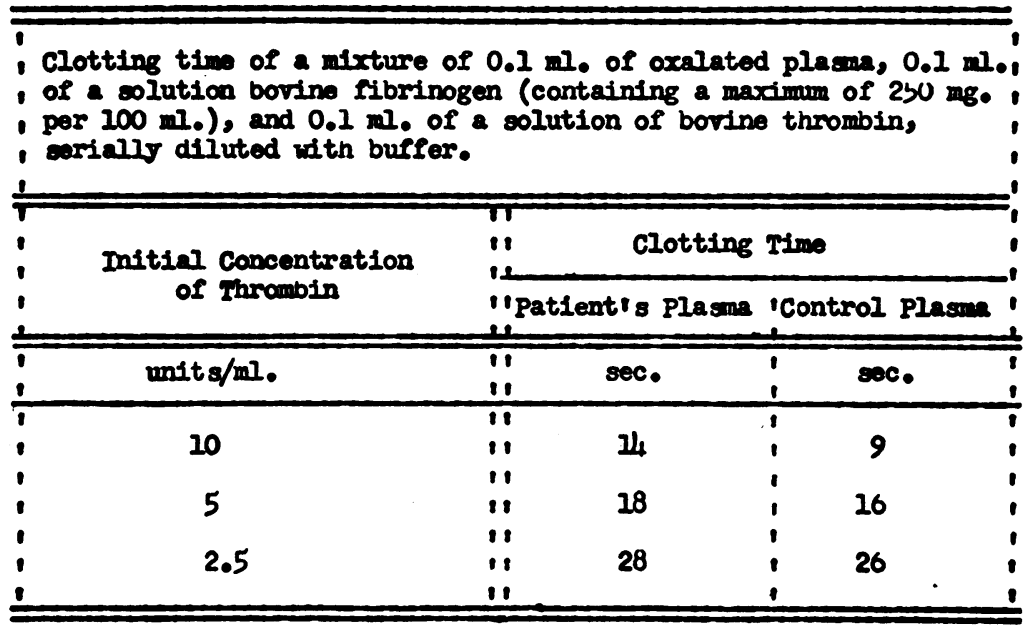

to a deficiency in some element needed for clotting, or to the presence of something interfering with the action of thrombin.

Since one of the samples of platelet-deficient plasma clotted, it seemed unlikely that excessive thrombin-inhibitory activity was present. When small amounts of thrombin were added to oxalated plasma, the clotting time of the patient's plasma was longer than that of a control plasma studied at the same time. The clots which formed when thrombin was added to the patient's plasma dissolved within five minutes, while those formed from normal plasma did not dissolve within the next 24 hours. In these experiments, the prolonged clotting time of the patient's plasma was more probably related to the small amount of fibrinogen present than to a thrombin inhibitor. The clotting time of a mixture of thrombin and fibrinogen decreases as the concentration of fibrinogen increases until a minimum time is reached. To eliminate the influence of the fibrinogen concentration on the clotting time, the patient's plasma was mixed with an equal portion of a solution of bovine fibrinogen and clotted with thrombin at $37^{\circ} \mathrm{C}$. Sufficient fibrinogen was added to make the clotting time independent of its concentration. With this technique, the thrombin-inhibitory activity of the patient's plasma was normal (Table I). Normal thrombin-inhibitory activity was also observed when the patient's

TABLE II

Fibrinolytic activity of oxalated plasma

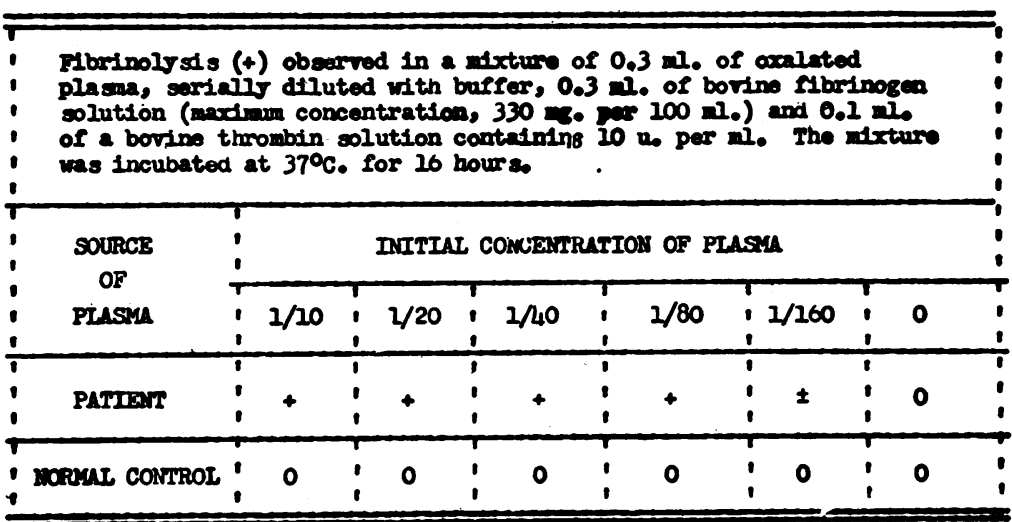


plasma was mixed with normal human plasma from which the prothrombin had been removed.

The foregoing observations showed that the patient's plasma contained fibrinogen which could be clotted by thrombin, and, in one of two samples of native plasma, clotted spontaneously. Paradoxically, whole blood failed to clot, and after incubation at $37^{\circ} \mathrm{C}$. for 205 minutes, did not clot when thrombin was added. A reasonable inference was that the fibrinogen in the patient's whole blood was digested by the plasma proteolytic enzyme before visible clotting took place. That this was likely, was demonstrated in the fol- plasma was excessively fibrinolytic, the fibrinogen determination was repeated using native plasma which had been kept at $0^{\circ} \mathrm{C}$. or less throughout this period. The fibrinogen in this plasma was clotted with thrombin; the fibrin was kept at room temperature for about 20 minutes while it was washed. The concentration of fibrinogen in this second specimen was $105 \mathrm{mg}$. per $100 \mathrm{ml}$. Thus, the amount of fibrinogen which seemed to be present in the patient's plasma decreased as it stood at room temperature.

The ability of the patient's plasma to lyse fibrin clots was measured directly. Mixtures of bovine

TABLE III

Protease inhibitory activity of oxalated plasma

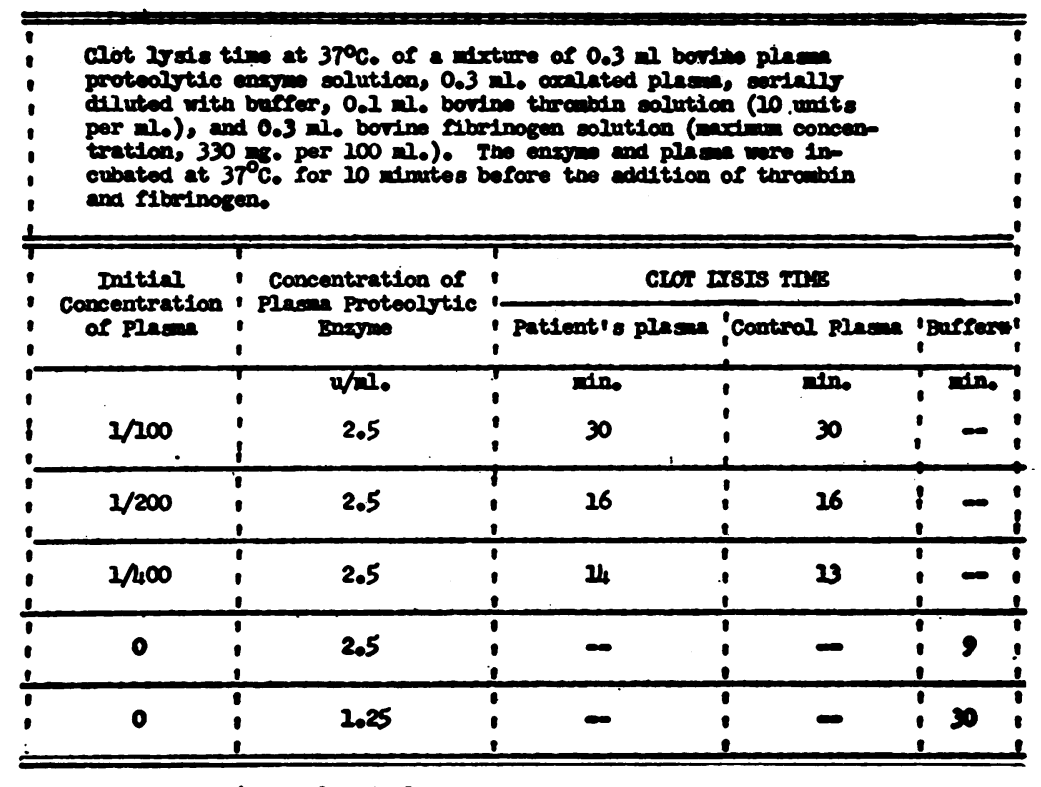

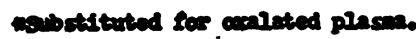

lowing manner. The concentration of fibrinogen was measured in a sample of oxalated plasma which had been separated from the blood cells by centrifugation at room temperature. The fibrinogen was clotted with thrombin, and the fibrin washed three times with sodium chloride solution. Ninety minutes elapsed from the time the blood was drawn until the washed fibrin was digested with sodium hydroxide. The concentration of fibrinogen in this sample was $39 \mathrm{mg}$. per $100 \mathrm{ml}$.

Two hours and ten minutes after the blood was drawn, when it became evident that the patient's fibrinogen and varying concentrations of plasma were clotted with bovine thrombin, and the clots were incubated at $37^{\circ} \mathrm{C}$. for 16 hours. The patient's plasma was fibrinolytic even when it was diluted almost 400 times (Table II). On the other hand, it was as effective as normal plasma in inhibiting the fibrinolytic activity of bovine plasma proteolytic enzyme (Table III), although this inhibition was observed only when the plasma was diluted beyond the point where its fibrinolytic activity was demonstrable.

The patient's blood was studied for the presence of other defects in the clotting mechanism. 
TABLE IV

Effect of oxalated plasma on the clotting time of recalcified hemophilic plasma

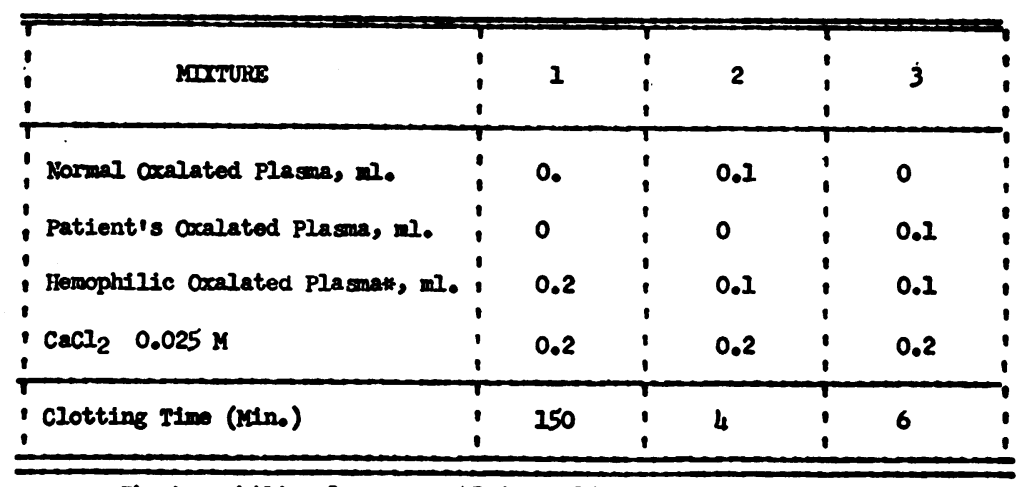

whe hemophilic plasma was 17 dags old.

The platelet count was $62,000 / \mathrm{mm}^{3}$. The prothrombin time was 28.6 seconds compared with a control of 16.8 seconds. This prolongation of the prothrombin time might have been due to a deficiency in prothrombin or in some other clotting element. The clotting time of a mixture of equal portions of the patient's oxalated plasma, normal prothrombin-deficient plasma, thromboplastin and calcium chloride was 30.3 seconds, compared with a control of 24.6 seconds. Presumably, therefore, hypoprothrombinemia was present in the patient's plasma when the test was performed.

The plasma proteolytic enzyme has not been reported to digest the substance lacking in hemophilic plasma. The recalcified clotting time of stored hemophilic plasma was shortened almost as much by the patient's plasma as by normal plasma (Table IV).

None of the experiments thus far described suggested that the patient's plasma contained a circulating anticoagulant. None the less, the pa- tient's platelet-deficient plasma prolonged the clotting time of normal whole blood (Table V). This effect was probably due to plasma's excessive proteolytic activity rather than to an anticoagulant. Twenty-four hours later, the patient's platelet-deficient plasma no longer prolonged the clotting time of normal whole blood.

\section{DISCUSSION}

A hemorrhagic state due to the destruction of prothrombin or fibrinogen by the proteolytic enzyme of plasma is a very rare phenomenon. Tagnon, Levenson, Davidson, and Taylor (5) described a woman who died after a severe post partum hemorrhage despite transfusion of blood and hysterectomy. A mixture of fibrinogen and the patient's plasma clotted, but the clot dissolved within one hour. The case of another woman who had a severe uterine hemorrhage associated with abruptio placentae was reported by Weiner,

TABLE V

Effect of patient's native plasma on the clotting time of normal blood

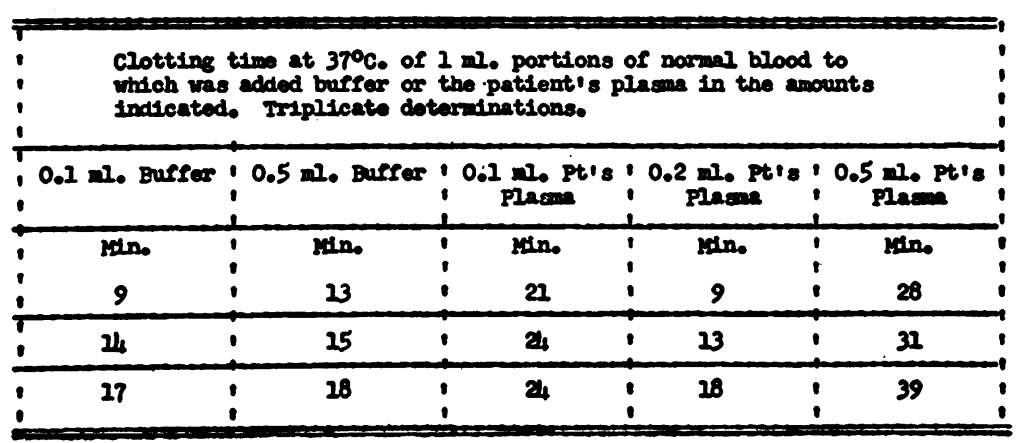


Reid, and Roby (8). Six hours after the onset of hemorrhage, when the patient had received $1,500 \mathrm{ml}$. of blood, a specimen of blood seemed to gel in six minutes but 15 minutes later was completely liquid and no fibrinogen could then be detected in the specimen. A lysin which digested a fibrin clot was demonstrable. No other bleeding phenomena were observed and the patient recovered after intravenous injection of fibrinogen. Mathey and his associates (9) described five patients who died of hemorrhage during pulmonary lobectomy or pneumonectomy. In each case, hemorrhage seemed to be due to afibrinogenemia caused by abnormal plasma proteolytic activity.

In the patient described in the present report, the concentration of fibrinogen was sufficiently high to permit clotting to take place. None the less, the patient's whole blood did not clot. The fibrinogen in the patient's plasma appeared to have been digested by the proteolytic enzyme of plasma before clotting occurred. The evidence that fibrinogenolysis actually took place in vivo is necessarily indirect. The sample of blood studied was obtained after the patient had been transfused with $3,000 \mathrm{ml}$. of blood, or almost half the normal circulating blood volume. If the average amount of fibrinogen in this transfused blood was $200 \mathrm{mg}$. per $100 \mathrm{ml}$. of plasma, an amount considerably less than the average of normal blood, then the specimen of blood which was studied should have contained almost $100 \mathrm{mg}$. of fibrinogen per 100 ml. of plasma from the transfused blood alone. Actually, the concentration in this specimen was about $105 \mathrm{mg}$. per $100 \mathrm{ml}$. Therefore, it is likely that the fibrinogen in the patient's blood was being destroyed or removed during life. A specimen of blood drawn agonally contained only $33 \mathrm{mg}$. of fibrinogen per $100 \mathrm{ml}$. of plasma, further evidence that the fibrinogen which the patient received from the transfused blood was being destroyed.

The mechanism which resulted in the activation of the plasma proteolytic enzyme in this patient remains unexplained. It has been suggested that the cells of various tissues can activate the precursor of the plasma proteolytic enzyme (15-17). As Macfarlane and Biggs (18) have pointed out, however, the mechanism of activation of this enzyme is most complex. Many diverse substances influence the clot lysis time in the test tube, but the relationship between observations concerning fibrinolysis in vitro and in vivo is not clear.

The patient also had slight hypoprothrombinemia and thrombocytopenia. Neither defect was of sufficient magnitude to produce her profound hemorrhagic state, but it is possible that they may have played a contributory rôle.

The patient who has been described had pancreatic carcinoma. The question arises whether the phenomena observed were not due to the action of trypsin which entered the circulation. Pancreatic trypsin will digest both fibrinogen and fibrin. However, trypsin promotes the clotting of oxalated plasma. In none of the experiments performed in vitro was there evidence that the patient's oxalated plasma would clot bovine fibrinogen unless thrombin was added. Moreover, human plasma in high dilution inhibits the lytic action of trypsin. Consequently, it seems unlikely that the hypofibrinogenemia observed in this patient was the result of digestion by pancreatic trypsin.

Treatment in the patient under study was ineffective, but the pathogenesis of the hemorrhagic state was not recognized until she had expired. The transfusion of blood provides large amounts of the protease inhibitors of plasma, but there was no evidence that the patient's blood was deficient in these substances. Perhaps the intravenous injection of large amounts of soy bean inhibitor (19) might have arrested the process, but this substance not only inhibits the proteolytic enzyme of plasma (20), but is anticoagulant as well (21), and its use may have substituted one cause of hemorrhage for another.

\section{SUM MARY}

A fatal hemorrhagic state was observed in a patient undergoing surgery for carcinoma of the head of the pancreas. The patient's blood was incoagulable despite the presence of appreciable amounts of fibrinogen. Study of the patient's blood indicated that its failure to clot was associated with excessive plasma proteolytic activity.

\section{ACKNOWLEDGMENTS}

It is a pleasure to acknowledge the technical assistance of Mrs. Rosemary Ashe and Mrs. Velma H. Axelrod. 


\section{REFERENCES}

1. Goodpasture, E. W., Fibrinolysis in chronic hepatic insufficiency. Bull. Johns Hopkins Hosp., 1914, $25,330$.

2. Macfarlane, R. G., and Biggs, R., Observations on fibrinolysis: spontaneous activity associated with surgical operations, trauma, etc. Lancet, 1946, 2, 862.

3. Ratnoff, O. D., Studies on a proteolytic enzyme in human plasma. IV. The rate of lysis of plasma clots in normal and diseased individuals, with particular reference to hepatic disease. Bull. Johns Hopkins Hosp., 1949, 84, 29.

4. Fantl, P., and Simon, S. E., Fibrinolysis following electrically induced convulsions. Australian J. Exper. Biol. \& M. Sc., 1948, 26, 521.

5. Tagnon, H. J., Levenson, S. M., Davidson, C. S., and Taylor, F. H. L., The occurrence of fibrinolysis in shock, with observations on prothrombin time and plasma fibrinogen during hemorrhagic shock. Am. J. M. Sc., 1946, 211, 88.

6. Frommeyer, W. B., and Epstein, R. D., Hemorrhagic diseases. New England J. Med., 1949, 241, 743.

7. Moloney, W. C., Egan, W. J., and Gorman, A. J., Acquired afibrinogenemia in pregnancy. New England J. Med., 1949, 240, 596.

8. Weiner, A. E., Reid, D. E., and Roby, C. C., Coagulation defects associated with premature separation of the normally implanted placenta. Am. J. Obst. \& Gynec., 1950, 60, 379.

9. Mathey, J., Daumet, P., Soulier, J. P., Le Bolloch, A. G., and Fayet, H., Hémorrhagies graves au cours d'interventions thoraciques par incoagulabilité sanguine due à la fibrinolyse. Mém. Acad. Chir., 1950, 76, 977.
10. Conley, C. L., Hartmann, R. C., and Morse, W. I., II, The clotting behavior of human "platelet-free" plasma : evidence for the existence of a "plasma thromboplastin." J. Clin. Invest., 1949, 28, 340.

11. Hartmann, R. C., Conley, C. L., and Lalley, J. S., Studies on the initiation of blood coagulation. I. The relationship of platelets to the clot-promoting effect of glass surfaces. Bull. Johns Hopkins Hosp., 1949, 85, 231.

12. Ratnoff, O. D., and Menzie, C., A new method for the determination of fibrinogen in small samples of plasma. J. Lab. \& Clin. Med., 1951, 37, 316.

13. Conley, C. L., Hartmann, R. C., and Morse, W. I., II, Circulating anticoagulants: a technique for their detection and clinical studies. Bull. Johns Hopkins Hosp., 1949, 84, 255.

14. Seegers, W. H., and Loomis, E. C., Prothrombin and fibrinolysin. Science, 1946, 104, 461.

15. Fleisher, M. S., and Loeb, L., On tissue fibrinolysins. J. Biol. Chem., 1915, 21, 477.

16. Astrup, R., and Permin, P. M., Fibrinolysis in the animal organism. Nature, 1947, 159, 681.

17. Tagnon, H. J., and Petermann, M. L., Activation of proplasmin by a tissue fraction. Proc. Soc. Exper. Biol. \& Med., 1949, 70, 359.

18. Macfarlane, R. G., and Biggs, R., Fibrinolysis: its mechanism and significance. Blood, 1948, 3, 1167.

19. Ham, W. E., and Sandstedt, R. M., A proteolytic inhibiting substance in the extract from unheated soy bean meal. J. Biol. Chem., 1944, 154, 505.

20. Mirsky, I. A., Inhibition of beta hemolytic streptococcic fibrinolysin by trypsin inhibitor (anti-protease). Science, 1944, 100, 198.

21. Macfarlane, R. G., and Pilling, J., Anticoagulant action of soya bean trypsin inhibitor. Lancet, 1946, 1, 888. 